\title{
Vernalização e corte do terço apical dos bulbos na produção e qualidade de sementes de cebola
}

\author{
Vernalization and cut of apical third of the bulbs in \\ yield and quality of seeds of onion
}

\author{
Marcos Gleidson Pereira dos Santos ${ }^{1 *}$; Wagner Ferreira da Mota ${ }^{2}$; Janiele Cássia \\ Barbosa Vieira ${ }^{3}$; Virgílio Jamir Gonçalves Mota Filho ${ }^{4}$; Ronaldo Porto Madureira ${ }^{5}$
}

\section{Resumo}

\begin{abstract}
A cebola (Allium cepa L.) pertence à família Alliaceae, sendo a segunda hortaliça em importância econômica. É cultura oleracea de alta relevância no centro-sul e no extremo sul, destacandose os estados de São Paulo, Rio Grande do Sul, Santa Catarina e Paraná. A bulbificação apenas se inicia quando a combinação dos fatores determinantes (fotoperíodo e temperatura) de cada cultivar é atingida. Contudo, pode ser cultivada em regiões tropicais com o uso da vernalização dos bulbos. O objetivo deste trabalho é identificar a eficiência na produção de semente de cebola em função do corte ou não dos bulbos submetidos a vernalização. As análises consistiram das variáveis: umidade; número de sementes; massa de sementes por umbela; número de umbelas; número de sementes por umbela; número total de flores e de flores fecundadas; número de sementes por cápsula; massa total de sementes; porcentagem de emergência de plântulas; primeira contagem do teste de germinação, índice de velocidade de emergência e massa de 100 sementes, utilizando as cultivares Baia Periforme e Texas Grano. O delineamento experimental foi de blocos casualizados com quatro repetições, constando 80 plantas por repetição, cada parcela foi conduzida com 20 plantas distribuídas em 4 linhas com 5 plantas com espaçamento de $20 \mathrm{~cm}$ entre plantas e entre linhas as quais foram avaliadas as 6 plantas centrais. A produção de sementes não variou entre as variedades Texas Grano e Baia Periforme. A variedade Texas Grano apresentou sementes com maior qualidade fisiológica. O corte ou não dos bulbos não alterou a qualidade fisiológica das sementes. Já a utilização de bulbos inteiros condicionou maior rendimento de sementes com maiores números de flores e de flores fecundadas na Baia Periforme, e ainda maiores valores de massa total de sementes, número de sementes por planta, número e massa de sementes por umbela nas duas variedades.
\end{abstract}

Palavras-chave: Allium cepa L, semente, vernalização, produção

\begin{abstract}
The onion (Allium cepa L.) belongs to the family Alliaceae, and the second vegetables in economic importance. It horticultural culture of high relevance, in central-south and in the far south, is highlighting the states of Sao Paulo, Rio Grande do Sul, Santa Catarina and Parana. The bulbificacion only begins when the combination of the determinants of bulbificacion (photoperiod and temperature) of each
\end{abstract}

\footnotetext{
${ }^{1}$ Eng $^{\text {o }}$ Agr $^{\circ}$, graduado pela Universidade Estadual de Montes Claros, UNIMONTES, Mestre em Produção Vegetal no Semiárido, e Doutorando em Fitotecnia pela Universidade Federal de Viçosa. E-mail: gleidsonagron@yahoo.com.br

${ }^{2}$ DSc. em Fitotecnia, Prof. do Dept ${ }^{\circ}$ de Ciências Agrárias da UNIMONTES. E-mail: wfmota@yahoo.com.br

${ }^{3}$ Eng $^{\mathrm{a}}$ Agr $^{\mathrm{a}}$, pela UNIMONTES, Mestranda em Fitotecnia pela Universidade Federal de Viçosa. E-mail: jani_cassia@yahoo.com.br

${ }^{4}$ Msc. em Produção Vegetal, Prof. do Dept ${ }^{\circ}$ de Ciências Agrárias da UNIMONTES. E-mail: virgiliojamir@yahoo.com.br

${ }^{5}$ Mestrando em Agronomia, Universidade Estadual de São Paulo, UNESP, São Paulo, SP. E-mail: ronaldomadureira22@yahoo. com.br

*Autor para correspondência
} 
cultivar is reached. It Can be grown in tropical regions with the use of vernalization of the bulbs. The objective of this study is to identify the efficiency in the production of seed, onion depending on the cut or not the bulb before the period of vernalization. The analysis of the variables consisted: humidity; number of seeds; mass of seeds for umbel; umbels number; number of seeds for umbel; total number of flowers and of fecundated flowers; number of seeds for capsule; total mass of seeds; emergency percentage; vigor percentage; index of emergency speed and mass of 100 seeds humidity; number of seeds; mass of seeds for umbel; umbels number; number of seeds for umbel; total number of flowers and of fecundated flowers; number of seeds for capsule; total mass of seeds; emergency percentage; vigor percentage; index of emergency speed and mass of 100 seeds, using the cultivars Baia Periforme and Texas Grano. The experimental design was randomized blocks with four replicates, there was 80 plants for replicate, each parcel was conduced with 20 plants distributed in 4 lines of 5 plants with spacing of $20 \mathrm{~cm}$ between plants and lines which was avaliated the 6 central plants. The seeds production not variated between cultivars Texas Grano e Baia Periforme. The cultivar Texas Grano showed seeds with more physiological quality. The cut or not cut of the bulbs not changed the physiological quality of the seeds. But utilization of whole bulbs resulted more yield of seeds with more flowers number and fertilized flower in Baia Periforme, more value of the total mass of seeds, number of seeds by plant and number and mass of seed by umbel in two cultivars.

Key words: Allium cepa $\mathrm{L}$, seed, vernalization, production

\section{Introdução}

A cebola (Allium cepa L.) é a segunda hortaliça em importância econômica no mundo, e terceira no Brasil, sendo amplamente cultivada para consumo fresco, como condimento ou na forma industrializada (SCHUNEMANN et al., 2006). O Brasil é o maior produtor da América do Sul, onde seu cultivo estende-se do nordeste ao extremo sul, cabendo à região Sul participação expressiva $(55,66 \%)$, seguida da região Nordeste $(26,02 \%)$ e Sudeste (19,30\%). Os estados de Santa Catarina, Bahia e São Paulo foram os maiores produtores em 2010. Minas Gerais destaca-se por apresentar a mais alta produtividade média observada no país, 56,47 tha-1 (IBGE, 2010).

A atividade de produção de sementes de hortaliças é muito tecnificada e importante no agronegócio de uma maneira geral. Do mercado mundial de sementes, que é estimado em aproximadamente 30 bilhões de dólares, quase 10\% (aproximadamente 2,4 bilhões de dólares) correspondem ao mercado de sementes de hortaliças segundo a Associação Brasileira do Comércio de Sementes e Mudas (ABCSEM, 2008). Nesse contexto o Brasil responde com menos de $4 \%$ do mercado mundial de hortaliças, tendo a necessidade de aumentar sua produção para aumentar sua competição a nível internacional. Logo o potencial de produção de sementes de cebola que necessitam de vernalização em condições tropicais de cultivo pode aumentar com a adoção adequada dessa técnica para essas regiões, devendo ser visada à máxima eficiência econômica em questão.

A cebola é uma oleracea de ciclo vital bienal, compreendendo uma fase vegetativa que culmina com a formação do bulbo no primeiro ano e uma fase reprodutiva, onde se dá o florescimento e, subseqüentemente, a produção de sementes no segundo ano, quando a cultivar está totalmente adaptada às condições climáticas da região. Um dos fatores principais para obtenção de alto rendimento de sementes é a ocorrência de máxima porcentagem de florescimento. A temperatura é o principal fator que condiciona o florescimento da cebola, sendo a faixa de $9-13^{\circ} \mathrm{C}$ considerada favorável para indução floral por meio da superação de dormência e diferenciação dessas gemas (REGHIN et al., 2005). A necessidade de frio para induzir o florescimento é a principal dificuldade na produção de sementes de cebola em muitos países tropicais. Conseqüentemente, a vernalização artificial tem sido utilizada para induzir o florescimento em cebola. No Brasil, apenas os estados de Santa Catarina e Rio Grande do Sul apresentam condições de produção de sementes sem a vernalização 
artificial dos bulbos-mãe (MULLER; CASALI, 1982). A autonomia para produzir sementes de cebola em regiões climaticamente não adequadas, como acontece com a região do semi árido Norte Mineiro, e outras de clima semelhante, com a utilização da vernalização de bulbos, condiciona o cultivo de cultivares adaptados e que já não são produzidas pelas empresas de sementes.

A fase reprodutiva inicia com o estímulo de frio recebido pelas gemas dos bulbos localizadas nas axilas de cada folha, em condições naturais e sob vernalização, havendo a emissão de escapos florais (CURRAH, 1981). Desta forma, o corte do terço apical dos bulbos sob vernalização condiciona uma maior exposição das gemas ao estímulo do frio aumentando o número de hastes e conseqüentemente maior produção de sementes.

A pesquisa foi desenvolvida com o objetivo de avaliar a produção e a qualidade de sementes de cebola das cultivares Texas Grano e Baia Periforme em função do corte ou não do terço apical dos bulbos, utilizando vernalização para possibilitar a produção no Norte de Minas Gerais.

\section{Material e Métodos}

O experimento foi conduzido no período de novembro de 2006 a setembro de 2007 na Horta de Ensino, Pesquisa e Extensão, da Universidade Estadual de Montes Claros - UNIMONTES, Campus de Janaúba-MG. Essa região se encontra inserida no semi-árido brasileiro, tendo o município as coordenadas de $15^{\circ} 47^{\prime} 18^{\prime \prime}$ de latitude Sul e $43^{\circ} 18^{\prime} 18^{\prime \prime}$ de longitude oeste, com altitude de 515 metros e clima Aw segundo a classificação de Köppen.

Aprecipitação média anualé de $740 \mathrm{~mm}$, dos quais $85 \%$ ocorrem entre os meses de novembro e março, com média de temperaturas máximas e mínimas de $32{ }^{\circ} \mathrm{C}$ e $19,5{ }^{\circ} \mathrm{C}$ respectivamente (SOUTO et al., 2001). O solo onde foi instalado o experimento é do tipo Neossolo Flúvico. Foi retirada uma amostra composta de solo da área experimental a $20 \mathrm{~cm}$ de profundidade, para análise da composição química e física de acordo com as metodologias propostas por (RIBEIRO et al., 1999). Conforme análise do solo foi constatada a seguinte composição química do solo: $\mathrm{pH}=6,5$; matéria orgânica $=2,6 \mathrm{dag} / \mathrm{kg} ; \mathrm{P}_{=}$ $80,6 \mathrm{mg} / \mathrm{dm}^{3} ; \mathrm{K}=86 \mathrm{mg} / \mathrm{dm}^{3} ; \mathrm{Na}=0,1 \mathrm{cmolc} / \mathrm{dm}^{3}$; $\mathrm{Ca}=2,6 \mathrm{cmolc} / \mathrm{dm}^{3} ; \mathrm{Mg}=1,0 \mathrm{cmolc} / \mathrm{dm}^{3} ; \mathrm{t}=3,9$ cmolc dm ${ }^{3} ; \mathrm{T}=4,9 \mathrm{cmolc} / \mathrm{dm}^{3} ; \mathrm{SB}=3,9 \mathrm{cmolc} / \mathrm{dm}^{3}$ e $\mathrm{V}=80 \%$. Sendo verificada a seguinte composição física: $84 \mathrm{~g} / \mathrm{kg}$ de areia; $12 \mathrm{~g} / \mathrm{kg}$ de silte e $4 \mathrm{~g} / \mathrm{kg}$ de argila. A adubação de acordo com a interpretação da análise de solo, constou das seguintes quantidades de fertilizantes: $50 \mathrm{~kg} / \mathrm{ha}, 50 \mathrm{~kg} / \mathrm{ha}$ e $120 \mathrm{~kg} / \mathrm{ha}$ de $\mathrm{P}_{2} \mathrm{O}_{5}, \mathrm{~K}_{2} \mathrm{O}$ e $\mathrm{N}$, respectivamente. A fertilização com $\mathrm{K}_{2} \mathrm{O}$ e $\mathrm{N}$ foi realizada com $30 \%$ no plantio e o restante, $70 \%, 40$ dias após o plantio, segundo recomendações de (RIBEIRO et al., 1999).

Para suprir a necessidade de irrigação foi adotado o sistema de irrigação por microaspersão, com turno de rega diário até a maturação fisiológica dos bulbos e das sementes.

Foi utilizado o delineamento experimental em blocos casualizados em esquema fatorial (cv. Texas Grano e cv. Baia Periforme) x (com e sem corte do terço apical dos bulbos), sendo utilizadas 4 repetições. Cada repetição apresentou cinco linhas de plantio, sendo as três internas consideradas úteis, com doze plantas por linha, totalizando 60 plantas na parcela e 24 na parcela útil .

As sementes foram semeadas diretamente no campo, sendo a colheita dos bulbos feita três meses após a semeadura para a cultivar Texas Grano e quatro meses para Baia Periforme. Posteriormente, os bulbos colhidos foram transportados para o laboratório de pós-colheita, onde foi realizado o corte do terço apical em $50 \%$ dos bulbos de cada cultivar. Em seguida todos os bulbos, com ou sem corte do terço apical, foram tratados com fungicida (Captan) para a prevenção de patógenos na pós-colheita.

$\mathrm{Na}$ sequência os bulbos foram colocados para vernalizar em câmara refrigerada à $8{ }^{\circ} \mathrm{C}$ por noventa dias e replantados no campo. Após 115 
dias os bulbos emitiram escapos florais, sendo que a colheita das umbelas ocorreu quando $40 \%$ das umbelas atingiram o ponto de maturação fisiológica (HAWTHORN; POLLARD, 1954). Após colhidas, as umbelas foram cuidadosamente acondicionadas em bandejas plásticas e tranportadas para um galpão sombreado, sendo espalhadas para completar a secagem em condições de ambiente, por aproximadamente duas semanas. Obtida a secagem das umbelas, indicada pela visualização das sementes e fácil desprendimento, as umbelas foram contadas, as cápsulas e sementes foram manualmente retiradas das flores fecundadas e, em seguida, foram colocadas em estufa a $38^{\circ} \mathrm{C}$, por 24 horas, atingindo grau de umidade em torno de $6 \%$.

As avaliações quantitativas constaram de massa de: sementes por umbela, dividindo-se a massa total de sementes pelo número de umbelas; número de umbelas, obtido por simples contagem; número de sementes por umbela, com o resultado do número de sementes, divide-se pelo número de umbelas; número total de flores e de flores fecundadas por simples contagem; número de sementes por cápsula, com o resultado do número de sementes por umbela, divide-se pelo número de flores fecundadas; massa total de sementes, por pesagem em balança analítica e massa de 100 sementes por meio de pesagem.

As avaliações qualitativas constaram de: porcentagen de umidade, germinação e índice de velocidade de germinação. A umidade e a qualidade fisiológicas foram avaliadas seguindo as orientações descritas nas Regras de Análises de Sementes (RAS) (BRASIL, 2009). Na qualidade fisiológica, procederam-se testes de germinação com a utilização de quatro repetições de 100 sementes, para cada tratamento, calculando-se a porcentagem de germinação. $\mathrm{O}$ vigor foi avaliado pela primeira contagem do teste de germinação, ou seja, contagem das plântulas normais do teste de germinação, no sexto dia (NAKAGAWA, 1994), e pelo IVG. Para evitar dormência, as sementes foram submetidas ao pré-esfriamento por sete dias, à temperatura de $8^{\circ} \mathrm{C}$. Depois, foram colocadas em câmara de germinação a $20^{\circ} \mathrm{C}$, por 12 dias, sendo então feito os testes de germinação e vigor.

Os dados obtidos foram submetidos para análise de variância. A comparação de médias dos tratamentos foi realizada pelo teste de Tukey, a 5\% de probabilidade.

\section{Resultados e Discussão}

O ciclo, de sementes, durou 90 e 120 dias, para as variedades Texas Grano e Baia Periforme, respectivamente. Esses valores são inferiores aos relatados na literatura onde se relata que o ciclo de produção de sementes de cebola varia de 130 a 180 dias (CURRAH, 1981, THOMAZELLI et al., 1990, REGHIN et al., 2004), em condições vernalizadas ou não, incluindo as variedades Texas Grano e Baia Periforme, utilizadas neste estudo. Essas reduções no ciclo, de 40 a 90 dias e de 10 a 30 dias, nas variedades Texas Grano e Baia Periforme, respectivamente, provavelmente ocorrem em função das maiores temperaturas encontradas na região do Norte de Minas Gerais, que promovem um metabolismo mais acelerado da planta. Isso pode trazer alguns benefícios como menor permanência da cultura no campo reduzindo custo de manejo, maior número de ciclos de cultivo por ano com maior rendimento anual, podendo compensar o custo com a vernalização.

A umidade, número de umbelas, número de sementes por umbela e número total de sementes não diferiram entre as variedades (Tabela 1). Quanto aos tratamentos, o uso de corte do bulbo proporcionou menor rendimento no número total de sementes e de sementes por umbela, isso provavelmente ocorreu devido a maior exposição dos bulbos cortados a fatores adversos do ambiente. Rodrigues et al. (2007) trabalhando com a variedade Baia Periforme obtiveram valores que variaram de 132 a 312 sementes por umbela. Valores semelhantes aos obtidos no presente trabalho, onde o rendimento médio foi de 301,58 sementes por umbela para a variedades Baia Periforme. Entretanto, o rendimento 
de sementes varia conforme a cultivar e condições edafoclimáticas. Destaca-se ainda que o rendimento obtido por ha foi de 485 e $437 \mathrm{~kg} \mathrm{ha}^{-1}$, para a Texas Grano e Baia Periforme, estando aproximadamente na faixa de $150-450 \mathrm{~kg} \mathrm{ha}^{-1}$ de sementes, valores estes que têm sido os mais comumentes obtidos (EMBRAPA HORTALIÇAS, 2004). O clima, principalmente a temperatura adequada explicam o bom rendimento.

Tabela 1. Massa total de sementes (MTS), número de sementes por planta (NSP), número de umbelas (NU), número de sementes por umbela (NSU), massa de sementes por umbela (g) (MSU) e número de sementes por cápsula (NSC) em função das variedades e do corte ou não do bulbo.

\begin{tabular}{ccccccc}
\hline Variedades & MTS & NSP & NU & NSU & MSU & NSC \\
\hline Texas Grano & $38,83 \mathrm{~A}^{*}$ & $9965,62 \mathrm{~A}$ & $25,62 \mathrm{~A}$ & $401,60 \mathrm{~A}$ & $1,56 \mathrm{~A}$ & $2,95 \mathrm{~A}$ \\
Baia Periforme & $35,09 \mathrm{~A}$ & $10237,63 \mathrm{~A}$ & $28,00 \mathrm{~A}$ & $331,58 \mathrm{~A}$ & $1,13 \mathrm{~B}$ & $2,63 \mathrm{~A}$ \\
\hline Corte do Bulbo & & & & & & \\
Com Corte & $23,49 \mathrm{~B}$ & $6507,62 \mathrm{~B}$ & $170,00 \mathrm{~A}$ & $295,62 \mathrm{~B}$ & $1,06 \mathrm{~B}$ & $2,91 \mathrm{~A}$ \\
Sem Corte & $50,44 \mathrm{~A}$ & $13695,63 \mathrm{~A}$ & $259,00 \mathrm{~A}$ & $437,57 \mathrm{~A}$ & $1,63 \mathrm{~A}$ & $2,67 \mathrm{~A}$ \\
CV $\%$ & 45,71 & 44,51 & 47,01 & 46,61 & 45,21 & 21,59 \\
\hline
\end{tabular}

*Médias seguidas da mesma letra na coluna não diferem significativamente entre si no nível de $5 \%$ de probabilidade pelo teste de Tukey.

Fonte: Elaboração dos autores.

A umbela pode apresentar 50 a 2000 flores. Após a fecundação, há o desenvolvimento da semente e, desde que a polinização seja eficiente, poderá haver a formação máxima de seis sementes por flor, o que se denomina cápsula (MELO; RIBEIRO, 1990). Nesta pesquisa foi obtida uma média de 2,95 sementes por cápsula para a Texas Grano e de 2,63 para a Baia Periforme (Tabela 1). Os resultados não diferenciaram significativamente entre as cultivares e os tratamentos sem e com corte do terço apical do bulbo. Essas médias foram baixas em relação ao potencial máximo produtivo que é de seis sementes por cápsula. Esse resultado foi semelhante ao encontrado por Rodrigues et al. (2007), que relataram média de 2 a 3 sementes por cápsula.

A massa total de sementes não diferiu entre as variedades, porém foi mais elevada quando não houve corte do bulbo (Tabela 1). A variedade Texas Grano obteve maior rendimento em massa de sementes por umbela do que a Baia Periforme (Tabela 1), também houve diferença significativa quanto ao ao corte dos bulbos, sendo que a não utilização de corte do terço apical do bulbo proporcionou maior rendimento em massa de sementes por umbela do que o tratamento com o corte. $\mathrm{O}$ rendimento foi inferior ao potencialmente esperado. No entanto, uma série de fatores no manejo podem ser calibrados em futuros trabalhos de pesquisa, podendo elevar o rendimento, como avaliar o período ideal de vernalização, época de plantio para obtenção do bulbilho e de sementes, adubação, irrigação entre outros.

$\mathrm{Na}$ variedade Baia Periforme, a não utilização do corte aumentou significativamente o número de flores e de flores fecundadas (Tabela 2), sendo explicado por serem mais ricos em reservas para o crescimento e desenvolvimento inicial dos meristemas e pela maior ocorrência de patógenos nos bulbos com corte do terço apical. O número de flores fecundadas e não fecundadas não alteraram na variedade Texas Grano com o corte ou não dos bulbos. Valendo ressaltar que um dos componentes de maior importância no rendimento de sementes é o total de flores por umbela (CASTELLANE; NICOLOSI; HASEGAWA, 1990). 
Tabela 2. Número total de flores e de flores fecundadas em função das variedades e do corte ou não do bulbo.

\begin{tabular}{ccccc}
\hline & \multicolumn{2}{c}{ Número de Flores } & \multicolumn{2}{c}{ Flores Fecundadas } \\
\hline Corte $\backslash$ Variedades & T. Grano & B. Periforme & T. Grano & B. Periforme \\
\hline Com Corte & 4436,50 a A & 2254,75 a B & 3194,00 b A & 1610,00 a B \\
Sem Corte & 5492,00 a A & 8638,50 a A & 3946,25 a A & 6800,25 a A \\
CV $-\%$ & 39,12 & & 37,99 & \\
\hline
\end{tabular}

* Médias seguidas da mesma letra minúscula na linha e mesma letra maiúscula na coluna não diferem significativamente entre si no nível de $5 \%$ de probabilidade pelo teste de Tukey.

Fonte: Elaboração dos autores.

Já com relação ao potencial fisiológico das sementes verificou-se que a porcentagem de germinação, primeira contagem e índice de velocidade de germinação foram mais elevados com $81 \%, 51 \%$ e $69 \%$, respectivamente, para a variedade Texas Grano, sendo encontrados para a variedade Baia Periforme, valores inferiores de 69 $\%, 23 \%$ e $44 \%$ (Tabela 3 ). Os valores de vigor foram relativamente baixos, com e sem corte e especialmente na Baia Periforme. Demonstrando que houve comprometimento da qualidade das mudas. Pois, Rodrigues et al. (2007) obteve valores de primeira contagem de $72 \%$ ao trabalhar com a Baia Periforme. Reghin et al. (2005) trabalhando com a cultivar Crioula obtiveram médias de porcentagem de germinação (PG) e primeira contagem (PC) de $95 \%$ e $86 \%$, respectivamente. Entretanto, (REGHIN et al., 2004) trabalhando com a mesma cultivar obtiveram valores de PG e PC de $85 \%$ e $70 \%$, respectivamente. Provavelmente os menores valores observados de potencial fisiológico encontrados na variedade baia periforme possam estar relacionados ao ponto de colheita das sementes, pois quanto mais atrasar o ponto de colheita menores serão as PG e VI (REGHIN et al., 2004). A definição do ponto de colheita e armazenamento ideais para as condições edafoclimáticas onde foi instalado o presente experimento devem ser melhor avaliados em futuros trabalhos.

Tabela 3. Teor de umidade (U\%), porcentagem de germinação (PG), primeira contagem (PC), Índice de Velocidade de Geminação (IVG) em função das variedades e do corte ou não do bulbo.

\begin{tabular}{lclll}
\hline Variedades & U\% & PG & PC & IVG \\
\hline Texas Grano & $9,00 \mathrm{~A}$ & $81,12 \mathrm{~A}$ & $51,00 \mathrm{~A}$ & $68,74 \mathrm{~A}$ \\
Baia Periforme & $11,57 \mathrm{~A}$ & $68,62 \mathrm{~B}$ & $22,87 \mathrm{~B}$ & $43,60 \mathrm{~B}$ \\
\hline Corte do Bulbo & & & & \\
Com Corte & $11,06 \mathrm{~A}$ & $73,00 \mathrm{~A}$ & $33,37 \mathrm{~A}$ & $52,76 \mathrm{~A}$ \\
Sem Corte & $9,52 \mathrm{~A}$ & $76,75 \mathrm{~A}$ & $40,50 \mathrm{~A}$ & $59,68 \mathrm{~A}$ \\
CV $-\%$ & 29,42 & 14,08 & 51,40 & 29,44 \\
\hline
\end{tabular}

*Médias seguidas da mesma letra na coluna não diferem significativamente entre si no nível de $5 \%$ de probabilidade pelo teste de Tukey.

Fonte: Elaboração dos autores.

Os tratamentos utilizados, ou seja, bulbos com corte ou sem corte, não afetaram o potencial fisiológico das sementes, ou seja, a porcentagem de germinação, a primeira contagem o índice de velocidade de emergência não diferiram entre os tratamentos com e sem corte do bulbo (Tabela 3). (REGHIN et al., 2005), trabalhando com tempo de vernalização também não encontrou diferenças significativas para essas características avaliadas.

Os bulbos inteiros apresentaram maior massa de 
100 sementes na variedade Baia Periforme (Tabela 4). Sendo os valores superiores aos observados por Rodrigues et al. (2007), o que explica a maior produtividade obtida no presente trabalho em relação às obtidas por estes autores. Já na Baia Periforme o corte ou não dos bulbos não alterou a massa de 100 sementes. Por outro lado, considerando os bulbos inteiros a Texas Grano apresentou maior massa de 100 sementes, enquanto entre os bulbos cortados não houve diferença entre as variedades para esta variável.

Tabela 4. Massa de 100 sementes em gramas em função das variedades e do corte ou não do bulbo.

\begin{tabular}{lll}
\hline Corte $\backslash$ Variedades & T. Grano & B. Periforme \\
\hline Com Corte & 0,36 a B & 0,35 a A \\
Sem Corte & 0,40 a A & 0,33 b A \\
CV $-\%$ & & 5,51 \\
\hline
\end{tabular}

*Médias seguidas da mesma letra minúscula na linha e mesma letra maiúscula na coluna não diferem significativamente entre si no nível de 5\% de probabilidade pelo teste de Tukey.

Fonte: Elaboração dos autores.

\section{Conclusão}

A produção de sementes não variou entre as variedades Texas Grano e Baia Periforme.

A variedade Texas Grano apresentou sementes com maior qualidade fisiológica. $\mathrm{O}$ corte ou não dos bulbos não alterou a qualidade fisiológica das sementes. Já a utilização de bulbos inteiros condicionou maior rendimento de sementes com maiores números de flores e de flores fecundadas na Baia Periforme, e ainda maiores valores de massa total de sementes, número de sementes por planta, número e massa de sementes por umbela nas duas variedades.

\section{Agradecimentos}

A UNIMONTES pelo apoio e a FAPEMIG pela concessão, ao primeiro e quinto autores de bolsa de iniciação científica e ao segundo autor, de Bolsa de Incentivo a Pesquisa e ao Desenvolvimento Tecnológico do Estado de Minas Gerais.

\section{Referências}

ASSOCIAÇÃO BRASILEIRA DO COMÉRCIO DE SEMENTES E MUDAS - ABCSEM. Pesquisa de mercado de sementes de hortaliças 2008. 2008. Disponível em: $<$ http://www.abcsem.com.br.>. Acesso em: 27 ago. 2008.

BRASIL. Ministério da Agricultura, Pecuária e Abastecimento. Regras para Análise de Sementes / Ministério da Agricultura, Pecuária e Abastecimento. Secretaria de Defesa Agropecuária. Brasília: Mapa/ACS, 2009. $399 \mathrm{p}$.

CASTELlANE, P. D.; NICOLOSI, W.; HASEGAWA, H. Produção de sementes de hortaliças. Jaboticabal: FCAV/FUNEP, 1990. $261 \mathrm{p}$.

CURRAH, L. Onion flowering and seed production. Scientific Horticulture, Kent, v. 32, p. 26-46, 1981.

EMBRAPA HORTALIÇAS. Sistema de produção de cebola (Allium cepa L). 2004. Disponível em: <http:// www.cnph.embrapa.br/sistprod/cebola/producao_de_ sementes.htm.>. Acesso em : 20 dez. 2009.

HAWTHORN, L. R.; POLLARD, L. H. Vegetable and flower seed production. New Yok: The Blakiston Company, 1954. $626 \mathrm{p}$.

INSTITUTO BRASILEIRO DE GEOGRAFIA E ESTATÍSTICA - IBGE. Agropecuária, produção agrícola. 2010. Disponível em: <http://www.ibge.gov. $\mathrm{br} /$ home/mapa_site/mapa_site.php\#indicadores $>$. Acesso em: 17 ago. 2011.

MELO, P. C.; RIBEIRO, A. Produção de sementes de cebola: cultivares de polinização aberta e híbridos. In: CASTELlANE, P. D.; NICOLOSI, W. M.; HASEGAWA, M. (Coord.). Produção de sementes de hortaliças. Jaboticabal, FCAV/FUNEP, 1990. p. 15-59. 
MULleR, J. J. V.; CASALI, V. W. D. Produção de sementes de cebola (Allium cepa L.). Florianópolis: EMPASC, 1982. 64 p.

NAKAGAWA, J. Testes de vigor baseados na avaliação das plântulas. In: VIEIRA, R. D.; CARVALHO, N. M. Testes de vigor em sementes. Jaboticabal: FUNEP, 1994. p. 1-24.

REGHIN, M. Y.; DALLA PRIA, M.; OTTO, R. F.; VINNE, J. Épocas de colheita de umbelas e comprimento da haste floral no rendimento e no potencial fisiológico de sementes de cebola. Horticultura Brasileira, Brasília, v. 22, n. 2, p. 286-289, 2004.

REGHIN, M. Y.; OTTO, R. F.; OLINIK, J. R.; JACOBY, C. F. S.; OLIVEIRA, R. P. Vernalização em bulbos e efeito no rendimento e potencial fisiológico de sementes de cebola. Horticultura Brasileira, Brasília, v. 23, n. 2, p. 294-298, 2005.

RIBEIRO, A. C.; GUIMARÃES, P. T. G.; ALVAREZ VENEGAS, V. H. (Ed.). Recomendações para o uso de corretivos e fertilizantes em Minas Gerais. $5^{a}$ aproximação. Viçosa, MG: Comissão de Fertilidade do Solo do Estado de Minas Gerais, 1999. 359 p.
RODRIGUES, A. P. D. A. C.; PIANA, C. F. B.; PESKE, S. T.; LUCCA FILHO, O. A.; VILLELA, F. A. Produção de sementes de cebola em sistemas convencional e de transição agroecológica. Revista Brasileira de Sementes, Brasília, v. 29, n. 3, p. 97-110, 2007.

SCHUNEMANN, A. P.; TREPTOW, R.; LEITE, D. L.; VENDRUSCOLO, J. L. Pungência e características químicas em bulbos de genótipos de cebola (Allium cepa L.) cultivados no alto vale do Itajaí, SC, Brasil. Revista Brasileira de Agrociência, Pelotas, v. 12, n. 1, p. 77-80, jan./mar. 2006.

SOUTO, R. F.; RODRIGUES, M. G.; MENEGUCCI, J. L. P. Situação da bananicultura na região norte de Minas Gerais. In: SIMPÓSIO BRASILEIRO SOBRE BANANICULTURA, 4., 1998, Campo Grande. Anais... Jaboticabal: FUNEP, 2001. p. 29-53.

THOMAZELLI, L. F.; BIASI, J.; YOKOYAMA, S.; BECKER, W.; FAORO, I. D.; SILVA, A. C. F.; MULLER, J. J. V.; GUIMARÃES, D. R.; ZANINI NETO, J. A.; VIZZOTTO, V. J. Produção de sementes de cultivares selecionadas de cebola em Santa Catarina. Pesquisa Agropecuária Brasileira, Brasília, v. 25, n. 11, p. 1607-1612, 1990. 